John Carroll University

Carroll Collected

2019 Faculty Bibliography

Faculty Bibliographies Community Homepage

2019

\title{
Who Posted That Story? Processing Layered Sources in Facebook News Posts
}

Anne Oeldorf-Hirsch

University of Connecticut - Storrs

Christina DeVoss

John Carroll University, cdevoss@jcu.edu

Follow this and additional works at: https://collected.jcu.edu/fac_bib_2019

Part of the Journalism Studies Commons, and the Mass Communication Commons

\section{Recommended Citation}

Oeldorf-Hirsch, Anne and DeVoss, Christina, "Who Posted That Story? Processing Layered Sources in Facebook News Posts" (2019). 2019 Faculty Bibliography. 37.

https://collected.jcu.edu/fac_bib_2019/37

This Article is brought to you for free and open access by the Faculty Bibliographies Community Homepage at Carroll Collected. It has been accepted for inclusion in 2019 Faculty Bibliography by an authorized administrator of Carroll Collected. For more information, please contact connell@jcu.edu. 


\title{
Who Posted That Story? \\ Processing Layered \\ Sources in Facebook \\ News Posts
}

\begin{abstract}
With social media platforms becoming primary news sources, concerns about credibility judgments and knowledge grow. This study $(N=233)$ experimentally tests the effects of multiple source cues on Facebook news posts on credibility and knowledge. Judgments of story credibility were directly influenced by media source cues, but not friend source cues. Involvement in the source topic moderated the effects of these source cues, such that particular combinations influenced credibility differently, and also influenced cognitive elaboration about the topic. Theoretical implications for cognitive mediation model of learning from the news and the heuristicsystematic model of information processing are presented.
\end{abstract}

\section{Keywords}

social media, online news, source cues, information processing

Social media sites such as Facebook have become important spaces for news consumption, but they are also riddled with issues regarding credibility and knowledge. The majority $(67 \%)$ of U.S. individuals now get at least some of their news on social media, with Facebook being the primary platform (Shearer \& Gottfried, 2017). Yet, there is mixed evidence for gaining knowledge about current events this way (Bode, 2016), maybe partly because social media news consumers skim headlines more than they read full stories (Gabielkov, Ramachandran, Chaintreau, 
\& Legout, 2016). Most social media users get their news passively, happening upon it when using these sites for other purposes (Matsa \& Mitchell, 2014). This may lead users to take shortcuts in assessing news content by relying on source cues, including the original media source and the friend who shared it. Reconciling these layered sources can influence how deeply individuals process this news content and what they learn from it.

This study experimentally tests the combined effects of news media sources and Facebook friend sources on perceptions of news credibility and knowledge outcomes. Of particular interest are cases in which sources conflict; for example, a news story posted by a close friend, but from a distrusted news source. Based on the heuristicsystematic model (HSM) of information processing (Chaiken, 1980) and the cognitive mediation model (CMM) of learning from the news (Eveland, 2001), the current research suggests that these cues lead to heuristic processing about credibility if they align, but may trigger systematic processing if they conflict. These conflicting cues should result in greater cognitive elaboration about the content of the story itself, which may lead to more knowledge gained from the story.

\section{Learning From News Content}

The CMM of learning from the news (Eveland, 2001) states that learning does not follow directly from exposure to news. Instead, surveillance gratifications drive attention to news media, which leads to elaborative processing of that media content, which only then leads to knowledge. Surveillance gratifications, or the need to gain information about one's environment, are what drive individuals to seek out news content. Attention is the mental focus given to that news content. Elaboration is a form of deeper processing, defined as "connecting new information to other information stored in the memory, including prior knowledge, personal experiences, or the connection of two new bits of information together in new ways" (Eveland, 2001, p. 573). This model has received substantial support across various media (Eveland \& Dunwoody, 2002; King, Jensen, Carcioppolo, Krakow, \& Sun, 2015; H. Lee, 2012) and for various types of elaboration (Eveland, Hayes, Shah, \& Kwak, 2005).

Yet, social media provides a different news environment, leading to different behaviors. News consumption on sites such as Facebook and Twitter is increasingly passive (Barthel \& Shearer, 2015). Individuals may not seek news actively in response to surveillance gratifications, but are instead incidentally exposed to it while they use these sites for other purposes. Research applying CMM to social media indicates that users engage with news stories after seeking them or being exposed to them even incidentally, through likes, shares, and comments, which offer visible indicators of attention as a cognitive process (Oeldorf-Hirsch, 2018). Yet, while these acts of engagement are linked to elaboration, or deeper processing of the story content, elaboration is not linked to knowledge. Instead, there is growing evidence that the "news-finds-me" perception that has resulted from social media use for news is negatively associated with political knowledge (Gil de Zúñiga, Weeks, \& Ardèvol-Abreu, 2017). Yoo and Gil de Zúñiga (2014) found that, after accounting for education, heavy Facebook users were 
less knowledgeable than light users. Similarly, Bode (2016) found a positive link between Twitter use and political knowledge, but no such link between Facebook use and political knowledge.

The gap between news use on social media and knowledge may be highlighting that users engage with the news posts, but not necessarily with the story content. One study found that $60 \%$ of news links shared on social media are never clicked on (Gabielkov et al., 2016). This leads to the question of what aspects of a news story post might trigger deeper engagement with and elaboration about news content. One potential trigger is conflicting media and friend sources, such as those that may be present on Facebook news story posts. When users can quickly judge the credibility of both sources, they may take the information presented in the story at face value. However, when these sources do not match in terms of credibility, users may need to consider the content more carefully, and thus may gain more knowledge from it.

\section{Assessing Credibility of News Content on Social Media}

According to the HSM of information processing, individuals will rely on heuristics to process a message when they can, to lighten their cognitive load (Chaiken, 1980). Heuristics are mental judgment rules stored in memory that provide shortcuts for processing information (Sundar, 2008). When presented with a large amount of information - such as the amount of news content available on Facebook - individuals use various cues to make decisions about that content. A cue is a piece of information provided by a medium that allows for evaluation of content, by triggering heuristics (Sundar, 2008). One such judgment is credibility, which can be assessed heuristically by considering the source.

Credibility is an assessment of whether some aspect of information is believable, accurate, trustworthy (Flanagin \& Metzger, 2000), unbiased, fair, objective (Sundar \& Nass, 2001), balanced, honest, current (Yale, Jensen, Carcioppolo, Sun, \& Liu, 2015), and authentic (Appelman \& Sundar, 2016). Judgments of credibility can be made about a source (e.g., a news organization), about a medium (e.g., social media platforms), or about a message (e.g., a particular story). For news stories posted on Facebook, these multiple facets of credibility can become blurred. The source may refer to the original media source or the Facebook friend who shared it, and these elements combined with the platform are conflated with message credibility. Specifically, message credibility is defined as "an individual's judgment of the veracity of the content of communication" (Appelman \& Sundar, 2016, p. 63). On social media, judgments of a story, or message credibility, are often made based on such cues surrounding the information. For instance, on Facebook, readers judge the content of news stories based on cues such as the friend who posted it (Turcotte, York, Irving, Scholl, \& Pingree, 2015) and the valence of the comments left on the posts about the stories (Winter, Brückner, \& Krämer, 2015). Therefore, this study focuses specifically on resulting perceptions of message credibility of news stories posted on Facebook, as an effect of the various sources that appear with the story in a user's news feed. 


\section{Source Cues}

How news receivers conceptualize news sources is key to their perceptions of news content in terms of credibility and other outcomes. Sundar and Nass (2001) present a typology of news sources with three different conceptions: source as a visible gatekeeper of the content, source as the media technology that delivers the content, and source as the receiver choosing the content for consumption, either the self or other users. In the case of Facebook, the site is the media technology, whereas the visible gatekeeper is the original media source (e.g., New York Times), and the receiver is the user of Facebook, either selecting the story for themselves or seeing the story posted by another user. Thus, this study focuses on two key sources present within the Facebook platform for a user: the gatekeeper (media) source and the receiver (friend) source.

First, users may assess the credibility of a news story shared on Facebook by the original source of a news story, or the media source. Experimental research indicates that individuals make credibility judgments of news stories based on source cues (Jo, 2005; Schmierbach \& Oeldorf-Hirsch, 2012; Westerman, Spence, \& Van Der Heide, 2014), and pay more attention to content presented from credible sources (Winter \& Krämer, 2014). While credibility of news media has been measured in diverse ways, trust of those media is at the base of credibility (Kohring \& Matthes, 2007). Turcotte et al. (2015) measured trust of a news outlet as a key outcome of friends sharing news articles on Facebook, which also determined whether they were going to seek information from the outlet in the future. Using the media source of the story as a cue, we expect that seeing a news story posted from a media source one trusts would be perceived as more credible than a story posted by a distrusted media source.

Second, users may assess the credibility of a news story shared on Facebook by a selecting source, in this case, the friend source. "Friends" on Facebook range in closeness from acquaintances to significant others. While closeness is a subjective concept encompassing feelings, perceptions, and behaviors (Parks \& Floyd, 1996), research indicates that individuals who consider themselves close to each other are similar to each other (Bahns, Crandall, Gillath, \& Preacher, 2017), are more closely aligned in attitudes (Davis \& Rusbult, 2001), and share more protective information with each other (Dubois, Bonezzi, \& De Angelis, 2016). Generally, news audience members have favorable views of news shared by others like them, or by those to whom they are connected (Sundar \& Nass, 2001). On Twitter, users tend to trust tweets from those whom they follow over tweets from trending topics or content searches (Morris, Counts, Roseway, Hoff, \& Schwarz, 2012). Likewise, on Facebook, news recommendations from friends have positive effects on media trust and news information seeking (Turcotte et al., 2015). Therefore, we predict that a story shared by a close friend would be judged as more credible than a story shared by a distant friend, or one to whom the receiver does not feel as close.

News stories shared on Facebook contain cues about both of these source types, which can either align or conflict, differentially influencing users' perceptions of news 
credibility. When both the original and selecting sources are trusted, judgments about the news story's credibility should be positive. Likewise, when trust of both sources is low, perceptions should be negative. Kang, Bae, Zhang, and Sundar (2011) experimentally investigated the effects of proximate, aggregate (e.g., Google news), and distal (e.g., New York Times) news source cues, and found that a news story is judged as most credible when both source cues are highly credible. Multiple source cues aligning in this way may lead to "cue-cumulation," an additive effect on news credibility perceptions (Sundar, Knobloch-Westerwick, \& Hastall, 2007).

When media and friend source cues conflict, the interaction of these multiple source cues may show varied effects depending on the combination. Kang et al.'s (2011) study of news source cues found that the proximate (aggregating) source was a better predictor of credibility judgments than the distal (original) source. However, in their study, the proximate source is the platform where the news stories were obtained, which serves as a media source, rather than a friend source. Hu and Sundar (2010) tested original and selecting sources in health information provided by doctors or laypersons and found that credibility was assessed primarily based on the original source, not selecting source. More recently, on Twitter, tweets (messages from an original source) versus retweets (others' tweets re-shared by a selecting source) show differing effects on credibility, but largely based on their original source (J. Y. Lee \& Sundar, 2013). Therefore, while these studies show some mixed source effects, there is stronger evidence that when media and friend sources conflict, credibility judgments should depend on the original source, in this case, the media source.

\section{The Moderating Role of Involvement}

According to HSM, individuals are more likely to employ systematic processing of information, or detailed processing of messages beyond simple cognitive shortcuts, under circumstances of high message involvement (Chaiken, 1980). HSM research shows that those to whom a persuasive message is less relevant are persuaded by heuristics, whereas those to whom a persuasive message is more relevant are persuaded by the strength of the argument (Chaiken, 1980; Petty \& Cacioppo, 1984). In a news context, Kang et al. (2011) found that the effects of conflicting proximate and distal news sources depend on news topic involvement. This indicates that those who are not particularly involved in a news topic may rely heavily on cues to make a credibility judgment about the story than those who are more involved in the topic. Therefore, we predict that for low involvement, both media and friend source will influence credibility more strongly than for high involvement. This leads to the following set of predictions:

H1: Perceptions of story credibility will be higher for a news story shared on Facebook from a trusted media source than one shared from a distrusted media source.

H2: Perceptions of story credibility will be higher for a news story shared on Facebook by a close friend than a news story shared by a distant friend. 
H3: Perceptions of story credibility will be higher when media and friend source cues align positively than when they align negatively.

H4: When source cues conflict, perceptions of story credibility will depend primarily on media source, such that credibility will be higher for a news story from a trusted media source posted by a distant friend than for a news story from a distrusted media source posted by a close friend.

H5: Involvement will moderate the relationship between source cues and story credibility perceptions such that under lower involvement, the (a) media source cue and the (b) friend source cue will have a stronger effect than under high involvement.

\section{Effects of Conflicting Cues on Knowledge}

When source cues on a Facebook news story conflict, individuals can no longer rely on one clear heuristic to judge a story's credibility, and may need to consider multiple cues or even other information. According to HSM research, systematic processing can be triggered by these types of conflicting or incongruent cues (Maheswaran \& Chaiken, 1991), as this conflict provokes individuals to consider the content of the information provided. In one study (Maheswaran \& Chaiken, 1991), when individuals were asked to assess a new product, they processed the information heuristically, relying on the consensus of others' ratings. However, those who were primed to think the task was of greater importance generated more attribute-focused thoughts, indicating that greater involvement in the task triggered greater systematic processing. Yet, when those ratings conflicted, even participants in the lower importance conditions showed more systematic thinking about the product itself, indicating that they could no longer rely on the consensus cues, as they were incongruent. These two factors interacted such that the incongruent ratings had a stronger effect on the low-importance task than the high-importance task because those who are more involved in the task are already processing information more systematically and thus were not as affected by cues.

Extending this to news content, the level of involvement in a news story is likely to impact the depth of information processing, or in the case of news, cognitive elaboration (Eveland, 2001). High involvement should lead to greater elaboration. However, for low involvement, conflicting news sources may also trigger systematic processing, or greater elaboration about the story. Furthermore, involvement is likely to moderate this relationship, such that conflicting cues will have a stronger effect on elaboration under low involvement than under high involvement.

H6a: High involvement will lead to greater elaboration about the news content than low involvement.

H6b: Conflicting source cues will lead to greater elaboration about the news content than aligned source cues.

H6c: Involvement will moderate the relationship between source cue alignment and elaboration, such that conflicting source cues will have a greater effect on elaboration under low involvement than under high involvement. 
In this regard, systematic processing is similar to the elaboration step in CMM (Eveland, 2001). While HSM focuses on the outcome of persuasion in various information contexts, CMM focuses on the outcome of knowledge in news contexts. According to HSM, persuasion can happen as a result of either heuristic or systematic processing, but is more persistent with systematic processing of information than heuristic processing of cues (Chaiken, 1980). Similarly, CMM research shows a direct link from news use to current events knowledge (e.g., Eveland \& Scheufele, 2000), but this path is stronger through the process of elaboration. Thus, greater elaboration about the news story should lead to greater knowledge about the topic. Furthermore, just as conflicting cues are likely to lead to systematic processing, conflicting news source cues should lead to greater knowledge about the topic through this elaboration step.

H7a: Greater elaboration will lead to greater knowledge about news content.

H7b: Conflicting source cues will lead to greater knowledge about the news content than aligned source cues, as mediated by elaboration.

\section{Method}

This experiment employed a 2 (Media source: high trust vs. low trust) $\times 2$ (Facebook friend source: close vs. distant) $\times 2$ (Topic: School shootings vs. Nobel Prize winner) experiment in which participants saw a real news story from an alleged news source purportedly shared by one of their friends on Facebook.

\section{Participants}

Participants $(N=233)$ were recruited from an introductory general education communication course at a large public northeastern U.S. university and received course credit for their participation. To be eligible, an individual had to be 18 years of age and have an active Facebook account. Participants ranged in age from 18 to 24, with a mean of 19 years old $(S D=1.23)$. More participants identified as female $(58.8 \%)$ than male (41.2\%). A majority (64\%) of the sample identified as White/Caucasian, 22\% identified as Asian/Asian American, 4\% as Black/African American, 4\% Hispanic/ Latino/a, and $4 \%$ mixed race/ethnicity.

\section{Procedure}

The experiment took place in a laboratory and was administered using the Qualtrics online survey platform, which randomly assigned participants to one of the eight experimental conditions. After consenting to the study, participants completed two sets of questions that provided the basis for the experimental manipulation.

For the media source manipulation, participants were asked to rank order 10 news sources from 1 (most trusted) to 10 (least trusted): Al Jazeera, BBC, BuzzFeed, CNN, Fox News, Huffington Post, New York Times, NPR, Washington Post, and Yahoo! 
News. These news organizations were selected to represent a range of trusted and distrusted news sources across the political spectrum in the United States (Mitchell \& Weisel, 2014).

For the friend source manipulation, participants were asked to list the full names of 10 Facebook friends that they would consider their closest friends, and 10 Facebook friends that they would consider their least close friends. They were asked to $\log$ in to Facebook and look at their friends list to complete this item, and told that the purpose of this item was to get them to think about their Facebook network. Mixed in with these items were questions about their engagement with news on social media, as well as filler items about their news consumption, news topics of interest to them, and their Facebook network, so as to disguise the manipulations.

Next, participants were told they were going to answer questions about a friend's recent Facebook post. Participants were asked to allow access to their Facebook account through a Facebook login that would pull information from their profile. They were presented with the same "Login with Facebook" button as seen on other websites where a Facebook account can be used to sign in, and profile information can be gathered. Participants were already logged in to Facebook from the earlier step of looking up their friends. Therefore, upon clicking the button, participants saw a popup screen that used animation to indicate that the survey site was connecting to Facebook to gather information, and then loaded a message that access had been granted. In actuality, the study software did not access the participants' Facebook accounts. This step to allegedly gain access was meant to ensure that when participants saw the subsequent software-generated Facebook post, they would believe it was an authentic post pulled from their Facebook feed.

After participants clicked to allow access, the following screen displayed a fictitious Facebook post about a news story allegedly shared by a friend (see "Stimuli" section). Below the Facebook post was the text and other content of the full original article, which participants were asked to read in full. After seeing the post and reading the article, participants completed items measuring the outcomes of interest.

After completing the study, participants were debriefed about the experimental design. They were informed that (a) their personal Facebook account was not accessed by the software program; (b) the post was not actually shared by their friend, but created for the purpose of this study; and (c) the story was a modified version of an original story, and the source of the story was based on their trust ratings and was not the actual source of the story.

\section{Stimuli}

Participants were randomly assigned to receive one of two news stories on different topics, which were intended to trigger high and low involvement in the story. The story intended to trigger high involvement in the topic was a story originally from CNN about school shootings in the United States (Smart, 2015). An article 
originally from Fortune about the Nobel Prize winner in economics was used to trigger low involvement in the topic (Smith, 2015). Original sources for both stories were removed, and text indicating the media source of the story as well as the Facebook friend who shared the post were piped in from each participant's previous answers using the Qualtrics piped text feature. The displayed media source of the news story was pulled from the news media source trust ranking participants completed earlier in the study, with either the most trusted or least trusted source displayed, depending on their assigned condition. For the displayed friend source of the Facebook post, a friend's name was pulled from either the list of friends that individuals listed earlier in the survey as close or the list of friends they considered distant, based on their assigned condition.

\section{Measures}

Topic involvement manipulation check. After seeing the post and reading the news story, participants rated each story on a 7-point Likert-type scale about how involved they were with the news topic $(1=$ not at all involved to $7=$ very involved $)$. A $t$ test determined that participants experienced significantly greater involvement in the story about school shootings $(M=2.83, S D=1.07)$ than the story about the economics Nobel Prize winner $M=1.97, S D=1.00, t(231)=-6.39, p<.001$, indicating that the topic manipulation was successful. Moving forward, we refer to these as high and low involvement stories.

Source identification. Participants answered an open-ended item about who the source was, to gauge what source they actually noticed. In total, $71 \%$ of the participants identified at least one of the sources displayed on the post, with $72 \%$ of those noting the media source, $26 \%$ of those focusing on the friend source, and $2 \%$ of those considering both as a collective source. Of those who did not identify either the media or friend sources, $1 \%$ identified Facebook as the source, $10 \%$ listed a source from the story, $11 \%$ indicated that they did not know or did not remember the source, and the remaining $7 \%$ did not list a source.

Because the sources that participants saw were based on their own ratings of media trust and friend closeness, data were not excluded based on this source check question. This practice is validated by previous research which indicates that participant data need not be excluded due to strict manipulation check failures because psychological effects of the manipulation can still occur (Aronow, Baron, \& Pinson, 2015). Rather, this source question provides descriptive data about what sources individuals notice in Facebook posts about news stories.

However, to test for the possibility that participants did not believe this source manipulation, we used the believability item from the source credibility scale (see below) to test for any systematic differences between manipulation conditions. Responses to this believability item do not differ by friend source: close versus distant, $t(231)=.18, p=.86$, whether they correctly identified a source, $F(1,231)=.1, p=$ .75 , or by whom they identified as the source in the open-ended identification item, 
$F(6,226)=.14, p=.99$, indicating that believability alone was not influenced by which friend source they were presented or noticed. Furthermore, participants who correctly identified the media source, friend source, or both sources $(n=165)$ did not differ significantly from those who did not identify one of these sources $(n=68)$ on credibility, $t(233)=-2.9, p=.78$; elaboration, $t(233)=-1.84, p=.07$; or knowledge, $t(233)=.06, p=.96$, indicating that there are no systematic effects of explicit source recall.

Story credibility. Participants rated their perceptions of the news story's credibility using a measure by Sundar (2001), indicating how well each of a list of adjectives described the news story on a Likert-type scale $(1=$ describes very poorly to $7=$ describes very well). Credibility was assessed with the adjectives accurate, believable, biased (reversed), fair, objective, sensationalistic (reversed), and had acceptable reliability after "biased" was dropped, $\alpha=.71(M=3.38, S D=.59)$.

Elaboration. Perse's (1990) television news elaboration measure was adapted and used for this study. Participants responded to five Likert-type items $(1=$ strongly disagree to 5 = strongly agree): "I tried to think of the practical applications of what I read," "I tried to relate the ideas in the story to my own past experiences," "I thought about how what I read related to other things I know," "I thought about what actions should be taken based on what I read," and "I found myself making connections between the story and what I've read and heard about elsewhere." The scale had high reliability, $\alpha=.87(M=3.22, S D=.88)$.

Knowledge. Knowledge was measured with five multiple-choice questions about each story with one correct answer and three incorrect answers (see the appendix). Answers were coded as $(1)=$ correct or $(0)=$ incorrect and summed. The average score was $2.57(S D=1.21)$ overall, with $M=2.23(S D=1.27)$ for the school shooting story and $M=2.91(S D=1.04)$ for the Nobel Prize story.

Demographics. Participants were asked to provide their age, sex, and ethnicity.

\section{Results}

We conducted full factorial analyses of variance (ANOVAs) to assess the main and interaction effects of story topic, media source, and friend source on the outcomes of credibility (for H1-H5) and elaboration (H6). We then conducted a multiple regression model to test the direct and indirect effects of story topic and source cues on knowledge (H7).

\section{Source Effects}

H1 stated that a news story posted on Facebook from a trusted media source would be perceived as more credible than one shared from a distrusted media source. The main 
effect for media source on credibility was significant, $F(1,225)=5.17, p<.05$, $\eta_{\mathrm{p}}^{2}=.02$, supporting H1. H2 predicted that a news story shared on Facebook by a close friend would be perceived as more credible than a news story shared by a distant friend. There was no significant main effect of friend source on credibility, $F(1,225)$ $=.32, p=.57$, showing no support for $\mathbf{H 2}$.

\section{Source Interaction Effects}

H3 predicted that aligned positive source cues would lead to higher credibility perceptions than when source cues aligned negatively, whereas $\mathbf{H 4}$ predicted that in the case of conflicting cues, media source cues would outweigh friend source cues in influencing perceptions of story credibility. Planned contrasts comparing the effects on credibility of aligned positive cue conditions (close friend and trusted media source) and the aligned negative condition (distant friend and distrusted media source) were not significant, $t(225)=-1.21, p=.23$, providing no support for H3. Planned contrasts comparing the conflicting conditions of trusted media source shared by a distant friend with distrusted media source shared by a close friend were significant, $t(225)=-2.01$, $p<.05$. However, the direction was opposite to that predicted by $\mathbf{H 4}$, such that credibility perceptions were higher for a story from a distrusted media source posted by a close friend than the reverse.

\section{Topic Involvement Moderation}

H5 predicted that under low involvement, (a) the media source cue and (b) the friend source cue would have a stronger effect on credibility than under high involvement. The two-way interaction between story topic and media source was not significant, $F(1,225)=.95, p=.33$. The two-way interaction between topic and friend source was also not significant, $F(1,225)=.32, p=.57$. Instead, story topic emerged in a significant three-way interaction with both source cues, $F(1,225)=4.87, p<.05$, $\eta_{\mathrm{p}}^{2}=.02$. Specifically, for the low involvement story (Nobel Prize winner), credibility was highest when the story was shared from a trusted source and by a close friend $(M=3.06, S D=.93)$, showing a cue magnification effect. Thus, H5a and H5b are not directly supported, but under low involvement, the combined cues influence credibility in the predicted way.

H6a stated that high topic involvement would lead to greater elaboration, whereas H6b stated that conflicting cues would also lead to greater elaboration, and H6c predicted that topic involvement would moderate the relationship between conflicting cues and elaboration. Story topic had a significant main effect on elaboration, $F(1,225)=37.46, p<.001, \eta_{\mathrm{p}}^{2}=.14$, such that the high involvement story (school shootings) led directly to greater elaboration, supporting H6a. Planned contrasts comparing conflicting cues with aligned cues on elaboration were not significant, $t(225)=.59, p=.55$, providing no support for H6b. However, planned contrasts comparing the low involvement story and aligned cue conditions with all other 
conditions showed a significant effect, $t(225)=3.46$, indicating that those who saw a low involvement story with aligned cues showed the least elaboration compared with those who either were more involved in the story or had conflicting cues. This provides some support for H6c.

\section{Elaboration and Knowledge}

H7 stated that (a) greater elaboration would lead to greater knowledge outcomes, and that (b) cue conflicts would lead to greater knowledge, as mediated by elaboration. To test these predictions, we used Model 4 of the PROCESS macro (Hayes, 2013), with 5,000 bootstrapping samples and $95 \%$ bias-corrected confidence intervals (BCa 95\% CIs). The interaction between media source and friend source was coded into a binary variable as either conflicting (low trust media/close friend or high trust media/distant friend), or aligned (high trust media/close friend or low trust media/distant friend), and used as the independent variable. The knowledge score was entered as the dependent variable, elaboration as the mediator, and story topic as a covariate. There was no effect of elaboration on knowledge, $\beta=.05$, $\mathrm{BCa} 95 \% \mathrm{CI}=[-.13, .24]$, or indirect effect of source cue conflict on knowledge through elaboration, $\beta=.00, \mathrm{BCa} 95 \% \mathrm{CI}=[-.01, .05]$. There was also no direct effect of source cue conflict on knowledge, $\beta=.16$, BCa 95\% CI $=[-.14, .46]$. Thus, $\mathbf{H 7} \mathbf{a}$ and $\mathbf{H 7 b}$ are not supported, indicating that source cue conflict does not lead to greater knowledge through elaboration.

\section{Discussion}

The results of this study show that media and friend source cues have nuanced combined effects on credibility perceptions and knowledge outcomes, particularly depending on story topic involvement. Media source cues had a direct effect on credibility, which adds to the body of research that indicates news content is judged by source cues (Jo, 2005; Winter \& Krämer, 2014). Yet, the closeness of the friend did not have a direct effect on credibility judgments, contrary to some previous research that indicates that we perceive information to be more credible from those whom we know or those who are more like us (Morris et al., 2012; Sundar \& Nass, 2001; Turcotte et al., 2015). Specifically, the results of this study differ from similar research by Turcotte et al. (2015) who found that outlet trust was higher for a news story shared by a friend than a media outlet, particularly if the friend was perceived to be an opinion leader. The present study is distinct in that individuals assessed the credibility of the story itself, rather than the outlet, and as a function of the combination of friend and media sources they either already feel close to or not, and trust or not, respectively. Thus, stories shared by opinion leaders may lead to greater media outlet trust (Turcotte et al., 2015), but perceived credibility of a particular story is only influenced by the friend sharing it in the context of existing media source trust and story topic involvement. 
Friend source cues came into play when the news story came from a distrusted media source. The combination of media and friend source cues did lead to different effects on credibility, depending on whether these cues aligned. Positively aligned cues were no different in determining credibility perceptions than negatively aligned cues, but a story from a distrusted media source shared by a close friend was judged to be more credible than a story from a trusted media source from a distant friend. This indicates that when the media source is not trusted, having it shared by a close friend raises the credibility of the story. These results provide some more evidence for the question of which source is more important in assessing news credibility when there are multiple sources to consider. While $\mathrm{Hu}$ and Sundar (2010) found that original sources had stronger effects on credibility, Kang et al. (2011) found proximate news sources to have more influence. Our research indicates that the original (media) source is more powerful overall, but that the proximate (friend) source becomes important when there is a conflict in trusted sources.

Story topic involvement was a key factor in credibility judgments. Credibility was highest for the high trust media/close friend combination for the low involvement story topic, indicating that under low involvement, individuals take all the shortcuts possible to make a credibility judgment based on the alignment of the most clearly positive cues. Under high involvement conditions, stories shared by a distant friend were judged as credible as those shared by a close friend as long as media trust was high, indicating that individuals are not relying on optimal source cue combinations in this case. These results provide support for HSM, indicating that in low involvement conditions, individuals are likely to engage in heuristic processing, whereas high involvement conditions are likely to trigger systematic processing in which individuals consider the information more carefully (Chaiken, 1980; Petty \& Cacioppo, 1984). These findings extend HSM to the news context, indicating that credibility perceptions of news content are also subject to different paths of processing, particularly dependent on involvement.

These results also highlight the importance of carefully considering the interplay of message and source factors in assessing credibility, as noted by Appelman and Sundar (2016). The two stories used in this study were selected to represent high and low involvement topics, which, in conjunction with source cues, were intended to produce an effect on overall message credibility. However, the stories do also vary in content in ways that could have other influences on credibility. For instance, while media source had an effect on credibility across stories, friend source cues differed by the story topic. This indicates that, in some cases, story content does play a role in assessing the story's credibility beyond simply relying on source cues.

Story topic directly impacted elaboration, such that the higher involvement topic also led to greater elaboration. However, conflicting source cues did not lead to greater elaboration than aligned cues as hypothesized. Instead, the effect of cue alignment on elaboration depended on involvement, such that elaboration was lowest when cues were aligned and involvement was low. That is, when individuals are not involved in the topic and there is no conflicting information to consider about the source of the information, cognitive elaboration is minimal. This provides some additional evidence 
that incongruent information can trigger deeper processing (Maheswaran \& Chaiken, 1991), in that congruent information under low involvement does not. These results provide an initial link between HSM and CMM, indicating that source cues can have an impact on cognitive elaboration in similar ways that they have an impact on systematic processing.

However, the predicted link between elaboration and knowledge was missing, providing no support for this element of CMM (Eveland, 2001) in this particular context. Yet, other research has failed to find this link in the social media context as well (Oeldorf-Hirsch, 2018). The results show that involvement in the topic led to more elaboration. It is not surprising that elaboration and involvement are highly correlated, as past research has used these concepts interchangeably (Perse, 1990). Instead, knowledge was influenced directly by the layered sources, depending on involvement. Knowledge means resulting from the low involvement story were relatively even across all media and friend sources, indicating that when individuals were not involved in the story, they did not process the information deeply enough for knowledge to vary by source cues. Yet, with a high involvement story, the conflicting cues of a news story shared by a distant friend from a trusted news source showed the highest knowledge mean for that story, indicating that these cues are being processed systematically. This indicates that perhaps deeper processing was triggered by conflicting cues, but that this is still distinct from the CMM concept of elaboration, which focuses more specifically on connecting the information back to existing knowledge.

This has implications for CMM (and HSM) in the social media context. Although no effects (other than involvement) were found on elaboration in the present study, previous research has found that greater elaboration of news content does occur on Twitter and Facebook, by way of engaging with news content through likes, comments, and shares (Oeldorf-Hirsch, 2018). Yet, while greater involvement in the story can lead to greater knowledge gains, elaboration does not. This indicates that on social media, knowledge gains may not depend on the act of tying the story back to one's existing knowledge based on engagement-a separate outcome - but on factors of involvement.

These results also hint at what participants notice as source cues on Facebook. When participants were asked to identify the source of the story, about half of all participants identified the news organization as the source, and about one fifth identified their friend as the source, with very few listing both as a combined source. This indicates that individuals do, in fact, use source cues, but not all in the same way. Furthermore, other research has found that Twitter users do not differentiate between sources in assessing the credibility of news content on the site (Oeldorf-Hirsch, Schmierbach, Appelman, \& Boyle, 2018), indicating that such source cues do not have strong effects. In the present study, while participants did judge credibility by some source cues, conflicts in these cues were not enough to trigger deeper processing of the information presented under low involvement conditions. 


\section{Limitations and Future Research}

As with most experiments, this study has several limitations to consider. First, the sample is relatively homogeneous in terms of age, education, and media use. While this demographic is the largest user of social media for news (Newman, Fletcher, Kalogeropoulos, Levy, \& Nielsen, 2017), future research on the effects of Facebook news sourcing must consider broader demographics. Second, while participants were asked to identify the source of the story, this item did not explicitly ask about both media and friend sources. Therefore, this item did not serve as a true manipulation check of the two source types. The responses to this question indicate that participants may not all have been paying attention to the same cues. Future research on Facebook news posts needs to more explicitly test the effects of noticing one, both, or neither source(s).

Third, it is possible that participants were not convinced by the friend source manipulation, particularly for the close friend conditions. It was not possible in this study to obtain participants' actual data about their Facebook interactions, and thus the information about close and distant friends had to be manually collected via the questionnaire and used in the study conditions. Due to the nature of the experimental manipulation, some expectancy violation may have occurred for some participants. Although we asked participants to rate how representative the story was of their friend, we did not explicitly test whether they believed both source manipulations, which is a limitation to understanding their effects. To address the possible expectancy violations in future research, both closed- and open-ended questions would be useful in assessing whether or not participants believed the manipulation in terms of the displayed media and friend sources.

Finally, this study only tested two news topics, which may have varied in ways other than involvement. In addition, the knowledge scores were significantly higher for the low involvement story, which may have been a function of the questions and their answers, which were unintentionally briefer for the economics story. Finally, future research will need to further test the effects of social media news use on knowledge, a theorized link that was not fully supported in this context.

\section{Conclusion}

If individuals are to get their news primarily from social media sites such as Facebook, it is crucial to understand how they process the news stories they find there. Given the passive nature of news consumption on social media, users take shortcuts the site makes available to judge the veracity of those stories, missing key information about the content. This study indicates that only when these shortcuts are not as clear-such as when source cues do not align - might content be judged in more depth. Yet, knowledge outcomes were unaffected by this discrepancy. Therefore, triggering deeper processing of information beyond the use of shortcuts for quick judgments will be the key to assessing and learning from news content posted on social media sites. 


\section{Appendix}

Knowledge items for school shooting story

(high involvement)

I. The study on mass killings found that one shooting increases the chances that others will occur within the following time frame:
a. 2 days
b. 5 days
c. 2 weeks
d. I month

2. Researchers believe that national media coverage plays a role in the spread of mass shootings because of this reported finding:

a. The killers were often found to be heavy consumers of news media coverage.

b. The spread of shootings was not location dependent.

c. Each shooting was more similar to the most recent shooting than any other shootings studied.

d. Survivors of the shootings talked about the experience using language similar to that used in news reports.

3. What percentage of mass killings appear to be a result of contagion?
a. Less than $10 \%$
b. $20 \%-30 \%$
c. $45 \%-50 \%$
d. More than $60 \%$

4. Katherine Newman, cited in the article, says that the biggest hurdle in preventing school shootings is:

a. Making it possible for people with information to report it to the authorities.

b. Consistent laws about open carry and concealed carry laws on campuses.

c. Staffing security on campuses.

d. Being able to predict which students will become a threat.

5. According to the article, which of these statements is true about how researchers gathered their data?

a. They were able to pull the data from an existing federal database of mass killings.

b. A federal database of mass killings exists, but the researchers were not able to gain access to it.

c. As part of this project, researchers built a federal database of mass killings.

d. No federal database of mass killings exists, so researchers had to gather their data elsewhere.
Knowledge items for Nobel Prize (low involvement)

I. Angus Deaton won the Nobel Prize for his work on:

a. Consumption, poverty, and welfare.

b. The cyclical history of the stock market.

c. Market failures such as the housing bubbling and the dot-com boom.

d. The psychology of harmful economic behaviors.

2. Deaton is recognized for using more extensive measures than is standard for what economic concept?
a. Wealth
b. Success
c. Prestige
d. Well-being

3. "Economic Sciences" was added to the list of Nobel Prizes in the following year:
a. 1895
b. 1920
c. 1968
d. 2011

4. Bill Gates found Deaton's views on foreign aid:
a. Favorable
b. Unfavorable
c. Neutral
d. His opinion is not mentioned in this article

5. Deaton is an expert in and critical of the rise of in developing nations:
a. Inequality
b. Crime
c. Racism
d. Disease 


\section{References}

Appelman, A., \& Sundar, S. S. (2016). Measuring message credibility: Construction and validation of an exclusive scale. Journalism \& Mass Communication Quarterly, 93, 59-79. doi:10.1177/1077699015606057

Aronow, P. M., Baron, J., \& Pinson, L. (2015). A note on dropping experimental subjects who fail a manipulation check. Social Science Research Network. Retrieved from https://papers. ssrn.com/sol3/papers.cfm?abstract_id $=2683588$

Bahns, A. J., Crandall, C. S., Gillath, O., \& Preacher, K. J. (2017). Similarity in relationships as niche construction: Choice, stability, and influence within dyads in a free choice environment. Journal of Personality and Social Psychology, 112, 329-355. doi:10.1037/ pspp0000088

Barthel, M., \& Shearer, E. (2015). How do Americans use Twitter for news? Pew Research Center. Retrieved from http://www.pewresearch.org/fact-tank/2015/08/19/how-do-americans-use-twitter-for-news/

Bode, L. (2016). Political news in the news feed: Learning politics from social media. Mass Communication and Society, 19, 24-48. doi:10.1080/15205436.2015.1045149

Chaiken, S. (1980). Heuristic versus systematic information processing and the use of source versus message cues in persuasion. Journal of Personality and Social Psychology, 39, 752766. doi:10.1037//0022-3514.39.5.752

Davis, J. L., \& Rusbult, C. E. (2001). Attitude alignment in close relationships. Journal of Personality and Social Psychology, 81, 65-84. doi:10.1037/0022-3514.81.1.65

Dubois, D., Bonezzi, A., \& De Angelis, M. (2016). Sharing with friends versus strangers: How interpersonal closeness influences word-of-mouth valence. Journal of Marketing Research, 53, 712-727. doi:10.1509/jmr.13.0312

Eveland, W. P., Jr. (2001). The cognitive mediation model of learning from the news: Evidence from nonelection, off-year election, and presidential election contexts. Communication Research, 28, 571-601. doi:10.1177/009365001028005001

Eveland, W. P., Jr., \& Dunwoody, S. (2002). An investigation of elaboration and selective scanning as mediators of learning from the web versus print. Journal of Broadcasting \& Electronic Media, 46, 34-53. doi:10.1207/s15506878jobem4601_3

Eveland, W. P., Jr., Hayes, A. F., Shah, D. V., \& Kwak, N. (2005). Understanding the relationship between communication and political knowledge: A model comparison approach using panel data. Political Communication, 22, 423-446. doi:10.1080/10584600500311345 
Eveland, W.P., Jr., \& Scheufele, D. A. (2000). Connecting news media use with gaps in knowledge and participation. Political Communication, 17, 215-237. doi:10.1080/105846000414250

Flanagin, A. J., \& Metzger, M. J.(2000). Perceptions of internet information credibility.Journalism \& Mass Communication Quarterly, 77, 515-540. doi:10.1177/107769900007700304

Gabielkov, M., Ramachandran, A., Chaintreau, A., \& Legout, A. (2016). Social clicks: What and who gets read on Twitter? In Proceedings of the 2016 ACM SIGMETRICS International Conference on Measurement and Modeling of Computer ScienceSIGMETRICS'16 (pp. 179-192). New York, NY: Association for Computing Machinery. doi:10.1145/2896377.2901462

Gil de Zúñiga, H., Weeks, B., \& Ardèvol-Abreu, A. (2017). Effects of the news-finds-me perception in communication: Social media use implications for news seeking and learning about politics. Journal of Computer-Mediated Communication, 22, 105-123. doi:10.1111/ jcc4.12185

Hayes, A. (2013). Introduction to mediation, moderation, and conditional process analysis. New York, NY: Guilford Press.

Hu, Y., \& Sundar, S. S. (2010). Effects of online health sources on credibility and behavioral intentions. Communication Research, 37, 105-132. doi:10.1177/0093650209351512

Jo, S. (2005). The effect of online media credibility on trust relationships. Journal of Website Promotion, 1, 57-78. doi:10.1300/J238v01n02 04

Kang, H., Bae, K., Zhang, S., \& Sundar, S. S. (2011). Source cues in online news: Is the proximate source more powerful than distal sources? Journalism \& Mass Communication Quarterly, 88, 719-736. doi:10.1177/107769901108800403

King, A. J., Jensen, J. D., Carcioppolo, N., Krakow, M. M., \& Sun, Y. (2015). Comparing theories of media learning: Cognitive mediation, information utility, and knowledge acquisition from cancer news. Mass Communication and Society, 18, 753-775. doi:10.1080/1520543 6.2015 .1027406

Kohring, M., \& Matthes, J. (2007). Trust in news media: Development and validation of a multidimensional scale. Communication Research, 34, 231-252. doi:10.1177/0093650206298071

Lee, H. (2012). Communication mediation model of late-night comedy: The mediating role of structural features of interpersonal talk between comedy viewing and political participation. Mass Communication and Society, 15, 647-671. doi:10.1080/15205436.2012.664239

Lee, J. Y., \& Sundar, S. S. (2013). To tweet or to retweet? That is the question for health professionals on Twitter. Health Communication, 28, 509-524. doi:10.1080/10410236.2012. 700391

Maheswaran, D., \& Chaiken, S. (1991). Promoting systematic processing in low-motivation settings: Effect of incongruent information on processing and judgment. Journal of Personality and Social Psychology, 61, 13-25. doi:10.1037/0022-3514.61.1.13

Matsa, K. E., \& Mitchell, A. (2014). 8 key takeaways about social media and news. Pew Research Center. Retrieved from http://www.journalism.org/2014/03/26/8-key-takeaways -about-social-media-and-news/

Mitchell, A., \& Weisel, R. (2014). Political polarization and media habits. Pew Research Center. Retrieved from http://www.journalism.org/2014/10/21/political-polarization-media-habits/

Morris, M. R., Counts, S., Roseway, A., Hoff, A., \& Schwarz, J. (2012). Tweeting is believ ing? In Proceedings of the ACM 2012 Conference on Computer Supported Cooperative Work-CSCW'23 (pp. 441-450). New York, NY: Association for Computing Machinery. doi:10.1145/2145204.2145274 
Newman, N., Fletcher, R., Kalogeropoulos, A., Levy, D., \& Nielsen, R. K. (2017). Reuters Institute digital news report 2017. Available from http://www.digitalnewsreport.org/

Oeldorf-Hirsch, A. (2018). The role of engagement in learning from active and incidental news exposure on social media. Mass Communication and Society, 21, 225-247. doi:10.1080/15 205436.2017.1384022

Oeldorf-Hirsch, A., Schmierbach, M., Appelman, A., \& Boyle, M. (2018). For the birds: Media sourcing, Twitter, and the minimal effect on audience perceptions. Convergence: The International Journal of Research into New Media Technologies. Advance online publication. doi:10.1177/1354856518780438

Parks, M. R., \& Floyd, K. (1996). Meanings for closeness and intimacy in friendship. Journal of Social and Personal Relationships, 13, 85-107. doi:10.1177/0265407596131005

Perse, E. M. (1990). Involvement with local television news: Cognitive and emotional dimensions. Human Communication Research, 16, 556-581. doi:10.1111/j.1468-2958.1990. tb00222.x

Petty, R. E., \& Cacioppo, J. T. (1984). The effects of involvement on responses to argument quantity and quality: Central and peripheral routes to persuasion. Journal of Personality and Social Psychology, 46, 69-81. doi:10.1037/0022-3514.46.1.69

Schmierbach, M., \& Oeldorf-Hirsch, A. (2012). A little bird told me, so I didn't believe it: Twitter, credibility, and issue perceptions. Communication Quarterly, 60, 317-337. doi: $10.1080 / 01463373.2012 .688723$

Shearer, E., \& Gottfried, J. (2017). News use across social media platforms 2017. Pew Research Center. Retrieved from http://www.journalism.org/2017/09/07/news-use-across-social -media-platforms-2017/

Smart, B. (2015, November 3). School shootings, mass killings are "contagious," study finds. CNN. Retrieved from http://www.cnn.com/2015/07/02/health/contagious-mass-killings -study/index.html

Smith, G. (2015, October 12). Meet the Princeton professor who just won the Nobel Economics Prize. Fortune. Retrieved from http://fortune.com/2015/10/12/angus-deaton-nobel-prize -economics/

Sundar, S. S., \& Nass, C. (2001). Conceptualizing sources in online news. Journal of Communication, 51(1), 52-72. doi:10.1111/j.1460-2466.2001.tb02872.x

Sundar, S. S. (2008). The MAIN Model: A heuristic approach to understanding technology effects on credibility. In M. J. Metzger \& A. J. Flanagin (Eds.), Digital media, youth, and credibility. The John D. and Catherine T. MacArthur Foundation Series on digital media and learning (pp. 73-100). Cambridge, MA: MIT Press. doi:10.1162/ dmal.9780262562324.073

Sundar, S. S., Knobloch-Westerwick, S., \& Hastall, M. R. (2007). News cues: Information scent and cognitive heuristics. Journal of the American Society for Information Science and Technology, 58, 366-378. doi:10.1002/asi.20511

Sundar, S. S., \& Nass, C. (2001). Conceptualizing sources in online news. Journal of Communication, 51, 52-72. doi:10.1111/j.1460-2466.2001.tb02872.x

Turcotte, J., York, C., Irving, J., Scholl, R. M., \& Pingree, R. J. (2015). News recommendations from social media opinion leaders: Effects on media trust and information seeking. Journal of Computer-Mediated Communication, 20, 520-535. doi:10.1111/jcc4.12127

Westerman, D., Spence, P. R., \& Van Der Heide, B. (2014). Social media as information source: Recency of updates and credibility of information. Journal of Computer-Mediated Communication, 19, 171-183. doi:10.1111/jcc4.12041 
Winter, S., Brückner, C., \& Krämer, N. C. (2015). They came, they liked, they commented: Social influence on Facebook news channels. Cyberpsychology, Behavior, and Social Networking, 18, 431-436. doi:10.1089/cyber.2015.0005

Winter, S., \& Krämer, N. C. (2014). A question of credibility-Effects of source cues and recommendations on information selection on news sites and blogs. Communications, 39, 435-456. doi:10.1515/commun-2014-0020

Yale, R. N., Jensen, J. D., Carcioppolo, N., Sun, Y., \& Liu, M. (2015). Examining first- and second-order factor structures for news credibility. Communication Methods and Measures, 9, 152-169. doi:10.1080/19312458.2015.1061652

Yoo, S. W., \& Gil de Zúñiga, H. (2014). Connecting blog, Twitter and Facebook use with gaps in knowledge and participation. Communication \& Society, 27, 33-48. doi:10.15581/003.27.4. $33-48$ 